\title{
THE QUALITY AND SAFETY OF HEALTH CARE SERVICES
}

\author{
Małgorzata NADZIAKIEWICZ \\ Silesian University of Technology \\ Alina MIKOLAJCZYK \\ Educational and Communication Consulting
}

\begin{abstract}
:
This article presents the quality, safety and assessment system as the important tools to supervise the health care organization. Quality is the sum of the properties and characteristics of a product, process or service that is appropriate to meet the complex requirements. In the case of health care is difficult to valuate quality, the universal indicators become useful tool. The development of quality indicators requires collecting of data and their proper processing. The high quality of medical services requires continuous improvement and adaptation to patients' needs. The quality indicators, for example, refer directly to the effects of therapy and are used to measure the success or failure of the applied therapeutic methods. Measuring the results of activities indicates only the level of quality of the services provided. The data helps to analyze information and improve the quality and safety of health care services.
\end{abstract}

Key words: quality, security, health care, assessment, management

\section{INTRODUCTION}

Quality should be understood as something that can be improved. It can refer to life, management, choice, service, information, etc. It can be treated as a tool for improving all areas of human activity. However, quality by itself is not a cure for all ailments from its very definition. It can be treated as a preventive measure, protecting against defects, it can also be a tool to improve the situation. It could also be an instrument that will prevent the appearance of faulty causes. Quality is the fulfillment of requirements and expectations, it is a path that leads to customer satisfaction. The quality assessment system is a tool to supervise organizational and technical factors within the organization. A certified system (ISO) is proof of order in all areas of the organization. However, this system should be a matter of constant attention, because the quality system is a living organism that must be regularly supervised and improved. The phenomenon of our time is the noticeable increase in the importance of the quality function. Quality is becoming the most important tool in market competition.

\section{QUALITY - HISTORICAL APROACH}

Former Prime Minister of Great Britain J. Major said, the Industrial Revolution took place in the nineteenth century. But now we are in the era of a Quality Revolution a period of change affecting all types of enterprises, organizations and people. Constantly improving quality, reducing costs is a must for any company that wants to stay on the market [12]. Quality management system is a system responsible for all aspects related to the quality of a product or services. Quality is an element inseparably connected with running economic activities and the life of every human being. The approach to quality has changed over the years, and now it does not only concern the technical aspects of products, but also the organizational aspects of the provision of services and the functioning of manufacturing processes in various organizations. The need for quality management is, therefore, enormous and almost every company currently displays care for its quality sphere. The Total Quality Management system (TQM) functions in the organization as a management subsystem alongside, eg., financial management, environmental management, occupational health and safety management and risk management. Nowadays, quality has become one of the most important problems of the current organization management. Understanding the sense, assumptions and quality methodologies is the first step to effective management and how to take actions to improve it. The key importance in the quality improvement process is the implementation of specific measures aimed at ensuring or improving quality. Improvement means the necessity to change conditions, change processes, change the law and introduce methods of providing quality care in health care services, as well as allowing for continuous monitoring and improvement. The improvement of the quality, and thus the introduction of changes, requires, first of all, involvement of the personnel providing care. The creator 
of quality management, E. Deming says that if one wants to achieve a real improvement in quality, give every employee the opportunity to participate in teamwork to organize and make changes. This applies to commitment to quality through teamwork, that is, joint problem solving, which brings contentment and a sense of pride from work, based on trust and cooperation and minimization of attempts to change inherent in their implementation [11]. The World Health Organization has adopted six principles for building and measuring the quality of healthcare:

1) Accessibility measured by the scale of the reasonable use of care, regardless of the limitations that may be associated with geographical location, money, time, age, language, transport, architecture of the building, etc.

2) Equality provision of care for the entire population based on identified needs, regardless of the class of specialists, their cultural, social, racial character or other personal characteristics.

3) Adequacy of types of health services, package of services, procedures are adapted to the real needs of returning communities, they are needed, expected, required by the unit.

4) Acceptance health care takes into account the cultural and religious values of recipients, meets their expectations.

5) Efficiency available resources, such as: money, buildings, equipment, employees, are the best and the most rationally used. The basic principle is: the highest effect at the lowest cost.

6) Efficiency care fulfills its task in terms of benefits and effectiveness [11].

The concept of quality in healthcare is a complex and multidimensional term. The solution to dilemmas related to various requirements of the parties interested in quality in health care may be a quality management system in healthcare. Attempts to ensure quality healthcare facilities go in three directions. The first is the implementation of management systems according to ISO standards in companies providing medical services. The second is accreditation as a way to ensure quality in health care and the third is TQM comprehensive management through quality in healthcare. When talking about quality in the field of medical services, its diversity should be taken into account in relation to other areas which are production for health care. This difference is particularly prevalent in the case of patients, as in the companies dealing in the production of medical equipment, pharmaceuticals, etc. for health care, the customer is removed from the manufacturing process. In contrast, in healthcare units, the patient and the service provider, a doctor, nurse, or technical worker must control quality of services. The first contact is very important and the patient should be given special attention, because it is the patient who evaluates the quality of services. All aspects of medical services give us the definition that says the most about quality assurance in the hospital. Quality is the sum of the properties and characteristics of a product, process or service that is appropriate to meet the complex requirements. The introduc- tion of a quality system should be a priority for both management and people creating health policy. Problems with the quality of services and products have been acknowledged for centuries. The first mention of responsibility for the work was included in the code of the King of Babylon Hammurabi in 1700 years BE. It mandates that if a building has defects, which risk the death of the owner, then the builder will be killed, and if the son of the owner dies, the builder's son will be killed. During the times of ancient Greece, Plato was the first to refer to the concept of quality, describing it as a degree of perfection. According to Aristotle, quality is a set of certain features that differentiate a given item from others [5].

It should be emphasized once again that quality is a complex concept, which changes with the passing of time and increasing human requirements. It is used in various contexts of meaning, such as relation to the quality of work, quality of life, quality of leisure time etc., variously defined by particular scientific disciplines. According to Garwin, quality has five features, namely absolute perfection, a service-oriented number of desirable features, a service-oriented, usability-oriented approach with requirements and price-oriented.

Nowadays quality is defined as compliance with requirements, a predictable degree of homogeneity and reliability at the lowest possible cost and adjustment to market requirements. In the nineties of the last century, Harvey and Green proposed to divide the definition of quality into five related groups: based on exceptions, perfection or homogeneity, adaptation to purpose, value for money, and transformation. Three variants of the exception-based definition can be distinguished as traditional, perfect and standard. In a traditional way, quality is defined as perfection, something special, characterized by high standards, giving high status to the user or owner. This is to promote an elitist view of high quality. Based on the definition of perfection, the terms refer to high standards, which can be defined as zero defects, and also the components of quality that are unattainable. The standard definition based on exceptions is directly related to the passage of specific quality tests. This is to eliminate defective services. Quality in this case is the compatibility of the service with the minimum requirements set by the service provider that is compliance with the norm. In the analysis of the definition based on perfection or homogeneity, the concept of quality from the standard should be distinguished, as quality means adequacy as to certain requirements that cannot be presented in the form of a standard. In this definition, the emphasis is on the process. Perfection means that everything works perfectly, the service meets the requirements. Perfection is also defined as the philosophy of prevention, i.e. making sure that there is no fault in any of the service processes. This approach is aimed at building a culture of quality. It consists in the fact that in each service is the responsibility for improving its quality. In this way, the system of interconnected teams receiving the input quality develops and is responsible for the output quality. In the case of definitions based on adaptation to destination, the quality depends on the purpose of the service. The service should be adapted to the 
destination. If it suits the purpose, it can serve as a model for achieving or measuring perfection. Otherwise, it may be completely useless [4].

In a value-based definition, quality is described by the price a potential customer can afford to pay for its requirements at a reasonable cost. Quality is compared to the level of requirements and is closely related to the cost. This definition does not consider the competitiveness effect, which is based on the assumption of quality improvement [4].

\section{EVALUATING QUALITY OF MEDICAL SERVICES}

Evaluation of quality of consumer goods is easier than evaluation of quality of health care services. The dishwasher cups which leave spots are poor quality and the consumer has the choice not to buy them anymore. The ability to make this distinction allows consumers to make a choice. In contrast, health care services are credence goods, an economic term referring to a type of good whose quality is more difficult for a consumer to evaluate. Consider a patient with cancer who is started on a chemotherapy regimen and subsequently feels nauseous and fatigued. To evaluate treatment quality requires medical expertise to contextualize patient experience is required. For example:

- Has her tumor shrunk?

- Are her symptoms associated with her chemotherapy?

- Are these symptoms likely to persist or resolve?

- Would a different treatment modality such as radiation therapy have been more effective or have resulted in fewer side effects?

Patients may know what their desired health outcomes are, but most lack the medical expertise needed to contextualize and fully evaluate the quality of care they receive.

\section{QUALITY IMPROVEMENT PROGRAM}

Outpatient healthcare organizations worldwide participate in quality improvement (QI) program. The importance of understanding the financial impact of the program is that in the program there are no established standard methods for empirically assessing QI program costs [2]. One possible reason for this phenomenon is that outpatient healthcare organizations must expend considerable resources to implement $Q$ I program, but they may never financially benefit from them [7]. The outpatient organizations would benefit from evaluations of no matter how much the program cost and run successfully. Such evaluations may also be valuable for policy makers designing and implementing financial incentives to encourage QI activities. There are several well-established methods for evaluating the societal value of healthcare program [8]. The cost-effectiveness analysis represent the high standard in the medical literature, these analyses do not provide the information organizations need to make informed business decisions [14]. Apart from these methods, the National Institute for Health and Clinical Excellence in the UK provides cost accounting tools for use by local health authorities to inform decisions regarding the adoption of new healthcare technologies [17]. Such tool are appropriate for regional policy decisions; however, but need further adaptation for evaluation of program from the perspective of health care organizations.

Table 1

Application of standard health economic evaluation methods to evaluate quality improvement program

\begin{tabular}{|c|c|c|}
\hline Method & Purpose & Data requirements \\
\hline $\begin{array}{l}\text { Costeffec- } \\
\text { tiveness } \\
\text { analysis }\end{array}$ & $\begin{array}{l}\text { Comparison of costs and } \\
\text { health effects of a quality } \\
\text { improvement program } \\
\text { versus usual care }\end{array}$ & $\begin{array}{l}\text { - Utilization data from } \\
\text { other healthcare provi- } \\
\text { ders } \\
\text { - Long-term health be- } \\
\text { nefits to patients }\end{array}$ \\
\hline $\begin{array}{l}\text { Cost-mini- } \\
\text { mization } \\
\text { analysis }\end{array}$ & $\begin{array}{l}\text { Comparison of the costs } \\
\text { of two program with iden- } \\
\text { tical health benefits }\end{array}$ & $\begin{array}{l}\text { Same as cost-effective- } \\
\text { ness analysis }\end{array}$ \\
\hline $\begin{array}{l}\text { Cost-be- } \\
\text { nefit ana- } \\
\text { lysis }\end{array}$ & $\begin{array}{l}\text { Comparison of program } \\
\text { costs and benefits, all } \\
\text { expressed in dollars }\end{array}$ & $\begin{array}{l}\text { - Health benefits of pro- } \\
\text { gram } \\
\text { - Costs of program }\end{array}$ \\
\hline $\begin{array}{l}\text { Time and } \\
\text { motion } \\
\text { studies }\end{array}$ & $\begin{array}{l}\text { Real time measurement of } \\
\text { changes in resource utili- } \\
\text { zation as a result of a qua- } \\
\text { lity improvement program }\end{array}$ & $\begin{array}{l}\text { Measurement of minute } \\
\text { to minute activities of } \\
\text { personnel affected by } \\
\text { quality improvement } \\
\text { changes }\end{array}$ \\
\hline
\end{tabular}

Source: [2].

\section{QUALITY ASSESSMENT IN HEALTH CARE}

The assessment of the quality of medical services is carried out using indicators and criteria relating to specific standards. The quality indicators in health care illustrate to what extent the recommended standard is achieved and implemented in a medical facility. The World Health Organization (WHO) defines quality in health care as the degree to which health services increase the probability of achieving expectations in terms of treatment effects and demonstrate compliance with current and professional knowledge. The quality of health care is a complex and interdisciplinary process. It can refer to both the improvement in the provision of medical services and factors important from the point of view of patient safety. Quality can be shaped by:

- the quality of the structure,

- the quality of the process,

- the quality of the result.

It is important to monitor and evaluate properly at every stage of the services. Indicators can be: positive indicators (the higher the index, the better the quality) or negative indicators (the higher the index, the worse the quality). The development of quality indicators requires the collection of data and their proper processing, so that it is useful information for those who monitor them. Therefore, an important element in determining indicators is to ensure that they are characterized by:

- significance - they should measure what is being measured and provide specific information necessary for management

- specificity - should be able to assign an assessment to them,

sensitivity - they should signal clearly changes,

availability - should be possible to achieve with reasonable effort, 
- reliability - the values should be similar with similar measurement.

The quality indicators used in healthcare can be divided into two types:

- universal (quality measures) - external indicators developed by organizations dealing with quality issues in healthcare and suitable for use in every medical facility,

- individual - internal quality indicators developed by a medical facility [10].

Quality is a key element in today's concept of customer value. The quality management system plays a very important role in creating processes that determine the effective functioning of medical facilities. However, one of the most important issues regarding the existence of a medical facility on the health care market is the maintenance and acquisition of new customers, in this case, patients. That is why, it is very important to ensure quality at the appropriate level, which is clearly noticeable at the first contact with the facility. Therefore, it is extremely important to take good care of patients, carry out the necessary tasks, pay attention to them and generally induce positive feelings about the experience. This leads to the customer loyalty for the offered medical services [10]. It is important to note indicators. There many different organizations which are responsible for universal indicators: ECHIM - European Community Health Indicators Monitoring, WHO - World Health Organization - Europe Division, ECDC - European Centre for Disease Prevention and Control and PATH - Performance Assessment Tools for Quality Improvement in Hospitals

The last one - PATH - organization has developed dimensions of the assessment of the quality of health services, guided mainly by the issue of ensuring the safety of care and patient orientation (Fig. 1) [16].

\begin{tabular}{|c|l|c|c|}
\hline $\begin{array}{c}\text { Clinical } \\
\text { effectivenes }\end{array}$ & Efficiency & $\begin{array}{c}\text { Staff } \\
\text { orientation }\end{array}$ & $\begin{array}{c}\text { Responsive } \\
\text { governance }\end{array}$ \\
\hline \multicolumn{3}{|c|}{ SAFETY } \\
\hline \multicolumn{3}{|c|}{ Patient centeredness }
\end{tabular}

\section{Fig. 1 The PATH conceptual model}

The dimensions of the quality assessment and indicators based on the PATH methodology can be used to ensure the proper quality.

Considering quality monitoring issues using indicators according to the classical theory of Donabedian, quality should be perceived and measured in three dimensions: -The quality indicators of the structure in practice mean the quality of staff education (specializations), access to a particular type of medical equipment, the number of personnel per patient, the number of medical procedures performed annually by the doctor, etc. The structural quality indicators illustrate the structural elements of medical facilities that are considered necessary in achieving high quality of care results. They indicate the potential of the facility, but not necessarily the effectiveness of its use. The process quality indicators are created on the basis of standards, guidelines for good practices in dealing with events, phenomena, activities separated from elements that make up the diagnostic or therapeutic process. They are elements distinguished as part of activities carried out in medical processes and have the greatest impact on the effect of health care. The essence of the process quality indicators is the identification of the elements and desired actions to be taken in relation to patients with specific health problems [3].

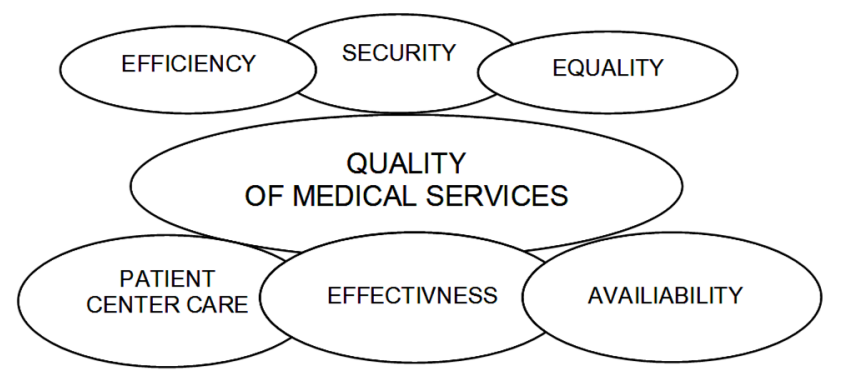

Fig. 2 The aspects of quality of health care services Source: [13].

The quality indicators of the result refer directly to the effects of therapy and are used to measure the success or failure of the applied therapeutic methods (Fig. 2). Measuring the results of activities indicates only the level of quality of the services provided. In constructing the result quality indicators, it is necessary to establish the so-called endpoint [1]. A positive example of the end point may be 5-year survival in cancer therapy, or negative-death caused by nosocomial infection.

The quality assessment of medical services is provided according to indicators and quality criteria. The most crucial element is constant monitoring and evaluating at every stage of the services [15].

\section{CONCLUSION}

The quality assessment of health care services must be provided according to indicators and quality criteria. The most important is constant monitoring and evaluating at every stage of the medical services [15]. The high quality of medical services requires continuous improvement and adaptation to the needs of customers or in this case, patients. High quality of health care is associated with a comprehensive approach to quality at every stage of the service. This means taking measures with the aim to satisfy the needs of the society members in terms of prevention, health promotion, diagnosis, treatment and the guarantee that the provided care meets the requirements of safety, effectiveness and efficiency. The continued uncertainty of the economic climate, changing demographics, and other pressures facing health care systems combine to cause a major quality issue. Organizations must move from multiple, disjointed initiatives focused on marginal cost reductions towards integrated strategies that improve outcomes by securing value of the money spent. Looking into new quality tools and assessment methods that can help medical organizations and patients build equitable and sustainable solutions [13]. Developing innovative approaches to help organizations transition from high-volume care to high-value care and shift the balance of care from the hospital to the community is ultimately, the goal. 


\section{REFERENCES}

[1] N. A. Bickell, A. D. Moss, M. Castaldi M. Organizational factors affect safety-net hospitals' breast cancer treatment rates. Health Serv Res;52:2137-55, 2017. doi: 10.1111/1475-6773.12605.

[2] S.E. S Brown, Chin M.H., E.S. Huang. Estimating costs of quality improvement for outpatient healthcare organisations: a practical methodology Qual Saf Health Care. 2007 Aug; 16(4): 248-251., doi: 10.1136/qshc.2006.019232.

[3] A. Czerw, U. Religioni, D. Olejniczak. Metody pomiaru oraz oceny jakości świadczonych usług w podmiotach leczniczych; Problemy Higieny Epidemiologicznej, 93, p. 271, 2012.

[4] J.J. Dahlgaard, K., Kristensen, G.K. Kanji. Podstawy zarzqdzania jakościq, PWN, Warszawa, pp. 22-25, 2000.

[5] A. Hamrol, W. Matura. Zarzqdzanie jakościq. Teoria i praktyka, PWN, Warszawa, p. 20, 2004.

[6] A. Hermas, L. Gajda. Systemy zarzqdzanie jakościq, Wydawnictwo Politechniki Śląskiej, Gliwice, 2005.

[7] E.S. Huang, Q. Zhang, S.E.S. Brown. The cost-effectiveness of improving diabetes care in US federally-qualified community health centers. Health Serv Res. Published Online First: 16 May 2007. doi: 10.1111/j.14756773.2007.00734.x.

[8] A. R. Gagliardi, A. B. Nathens. Exploring the characteristics of high-performing hospitals that influence trauma triage and transfer. J Trauma Acute Care Surg 2015; 78: 3005.doi: 10.1097/TA.0000000000000506.

\section{PhD. Małgorzata Nadziakiewicz}

Silesian University of Technology

Faculty of Organization and Management

Department of Applied Social Science

ul. Roosevelta 26, Zabrze, Poland

e-mail: malgorzata.nadziakiewicz@polsl.pl

\section{M.A. Alina Mikolajczyk}

ECC, Educational and Communication Consulting, Inc. 5310 N. Harlem Avenue, Chicago, USA e-mail: amikolaj@gmail.com
[9] R. J. Maxwell. Quality assessment in health. Br Med J 288, p.147, 1984.

[10] M. Nadziakiewicz. Marketing and Quality of Medical Services in the Times of New Technologies, Zeszyty Naukowe Politechniki Slaskiej, Gliwice, 122, p.143, 2018.

[11] A. Sułek. Zdrowie i zarzqdzanie, vol. V, 6, p. 26, 2003.

[12] A. Tuckman. The Yellow Trick Road, Total Quality Management and the Restructuring of Organization Studies, 5, p. 730, 1994.

[13] B. Verboom, P. Montgomery, S. Bennett. What factors affect evidence-informed policymaking in public health? Protocol for a systematic review of qualitative evidence using thematic synthesis. Syst Rev 2016; 5: 61.doi: 10.1186/s13643-016-0240-6.

[14] M. C. Weinstein, J. E. Siegel, M. R. Gold. The Panel on CostEffectiveness in Health and Medicine et al Recommendations of the Panel on Cost-Effectiveness in Health and Medicine. JAMA 19962761253-1258, 2007.

[15] S. H. Wu, Lee J., A comparison Study of Nursing Care Quality in Different working Status Nursing Staffs: an example of one Local Hospital. J Nurs Re, pp. 181-188, 2006.

[16] https://www.path.org [accessed 9 Feb. 2019].

[17] National Institute for Health and Clinical Excellence Costing tools. http://www.nice.org.uk/page.aspx?o= costingtools [accessed 9 feb. 2019]. 